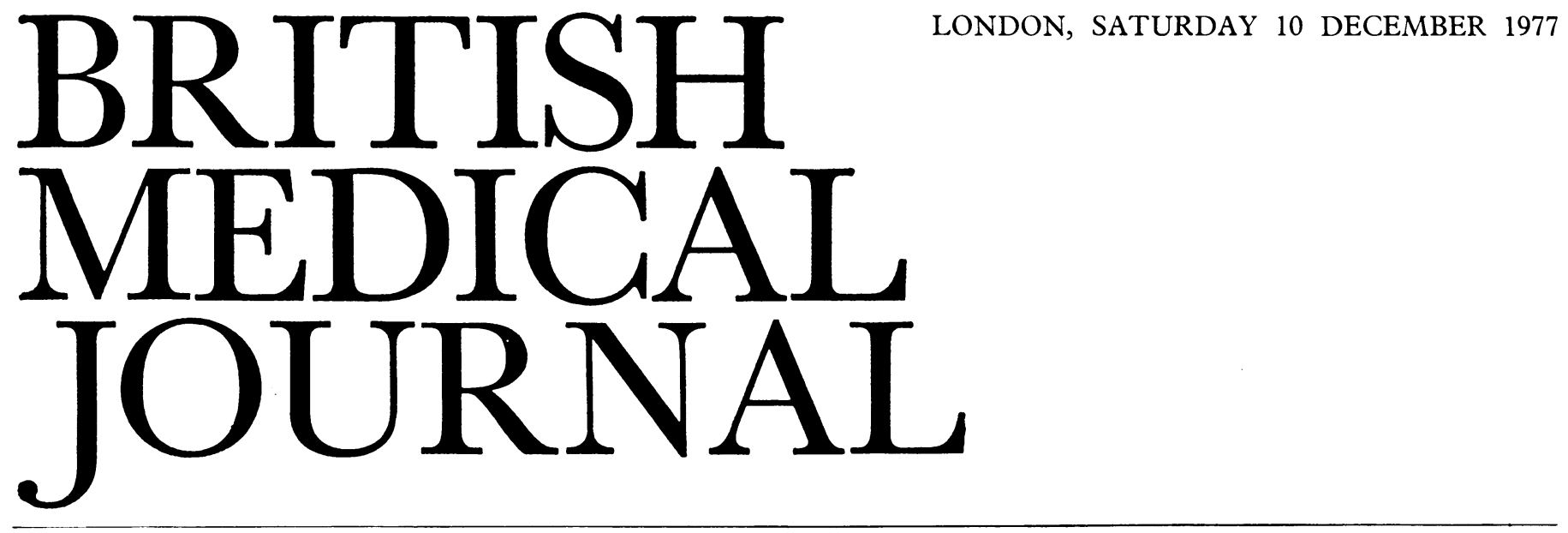

\title{
Carcinoma of the pancreas
}

The incidence of carcinoma of the pancreas is rising steadily in all Western countries. It has trebled in the United States since 1930 and doubled in England and Wales over the same period. Clearly we need to answer some important questions. Are any causes apparent? What features of the patient's history or what physical signs should suggest the diagnosis? Have any of the new methods of investigation made earlier diagnosis any easier? And, finally, in view of the appalling prognosis, is it not time that we reappraised surgical treatment?

Much of this ground has recently been well reviewed by Morgan and Wormsley. ${ }^{1}$ Several risk factors are now clearly linked with carcinoma of the pancreas. An association with cigarette smoking, at 10-15 per day, is now firmly established: Krain $^{2}$ has shown that the median age for pancreatic cancer is 10-15 years earlier in smokers than in non-smokers. The incidence of pancreatic carcinoma in patients with diabetes mellitus also appears to be twice that in the general population, and the development of diabetes in a middle-aged patient with no family history of the disease or a sudden tendency to instability in a diabetic who had been well controlled should raise the suspicion of an underlying carcinoma. Nevertheless, we have no evidence that pancreatitis (either acute or chronic) predisposes to malignant change. On the other hand, a carcinoma of the head of the gland or of the ampulla of Vater may occasionally present as acute pancreatitis. Diet, too, must be a contributory factor, and, though the mechanism is quite unknown, two suggestions have been made. Possibly modern methods of processing food may introduce a carcinogen; or alternatively the Western diet, rich in fat and protein, might induce a chronic hyperplasia of the pancreas with an increased turnover of cells, so increasing their susceptibility to carcinogens in general. Nevertheless, the nature of these carcinogens remains completely unknown, and Morgan and Wormsley ${ }^{1}$ emphasise that their identification is an important subject for further research.

What, then, of the symptoms? The classic description of a progressive painless jaundice holds true only in a minority of cases. Between $50^{\circ}$ " and $80^{\circ}$ " of patients with carcinoma of the pancreas present with pain, and up to $90^{\prime \prime}$ "have pain at some stage of their illness. This may be variable in location, and most often it is dull, aching, or boring; steadily progressive; and quite often worse at night. A minority of patients - perhaps $15-30^{\circ}$-present with pain in the back alone; and, since the onset is insidious and so many other much more common conditions present in the same way, early identification of possible cases is difficult-yet full investigation is needed if the diagnosis is not to be missed. Are there any pointers which may help in this selection? Weight loss, particularly if it is rapid and progressive, and an associated jaundice both indicate a need for urgent investigation. The other symptoms associated with carcinoma of the pancreas are so vague that they could be due to almost any other intraabdominal condition, while physical signs are of equally little help.

Once suspicion is aroused, however, what help can we derive from the results of investigations? Morgan and Wormsley's review confirms that few are of real value and they are far from simple. Expert cytological examination of the centrifuged deposit of pancreatic juice may confirm a diagnosis of carcinoma. The histological examination may be facilitated by the administration of tetracycline, since it may induce malignant cells to fluoresce. ${ }^{3}$ As a further refinement, the duct of Wirsung may be cannulated, so allowing direct collection of juice uncontaminated by duodenal contents, and it is now even possible to pass a brush through the cannula: the debris removed from within its bristles is said to give an even higher yield of malignant cells. ${ }^{4}$

Endoscopic retrograde pancreatography is becoming increasingly widely available, and its value in diagnosis has recently been reviewed by Cotton. ${ }^{5}$ A variety of appearances suggest or will confirm the presence of a carcinoma. The diagnostic accuracy is increased further if the examination is assessed in conjunction with expert selective angiography. ${ }^{6}$

But how far do these tests advance the patient's course? Morgan and Wormsley have to conclude that patients with carcinoma of the pancreas are often investigated for several months and that by the time the diagnosis is confirmed the tumour is often inoperable. While the EMI scanner or ultrasonography may pick up a few more cases at an operable stage, the overall picture remains gloomy, and there is a real need for a breakthrough in some new type of diagnostic procedure. Screening for carcinoembryonic antigen seemed a possibility, but the test has not proved sufficiently sensitive. Nevertheless, there are hopes that the newer procedure using oncofetal antigen may be more useful. ${ }^{\top}$

The results of the surgical treatment of carcinoma of the pancreas are almost equally discouraging, as was apparent when it was discussed at the last meeting of the Pancreatic Society of Great Britain and Ireland. Radical pancreaticoduodenectomy (Whipple's operation) has an operative mortality of about $20^{\circ}$ and its long-term results are poor $-0-2 \%$ five-year survival-so that many surgeons now adopt a policy of simple 
palliation by bypass for all cases. Nevertheless, the only hope of cure for these patients lies in surgical excision of the tumour. Would an even more radical approach be justified? There is evidence that Whipple's operation sometimes fails because the disease may be multicentric. Furthermore, the extent of the carcinoma may be difficult to assess at laparotomy, so that the plane of section at the neck of the pancreas may not be clear of the primary growth. Finally, division of the gland may allow shedding and seeding of malignant cells.

Total pancreaticoduodenectomy with splenectomy would overcome all these problems and would also permit a wider lymphatic clearance. No pancreaticojejunal anastomosis would be needed-another clear advantage, since leakage at this anastomosis is an important cause of the high operative mortality for Whipple's operation. On the debit side total pancreatectomy carries a considerably increased morbidity because of the metabolic problems produced. Nevertheless, a review of experience at the Mayo $\mathrm{Clinic}^{8}$ showed that many of the problems after total pancreatectomy could be attributed to recurrence of malignancy and that with modern medical management these patients can achieve a reasonable life. The salvage rate for carcinoma was better than expected, with a $25^{\%}$ three-year survival. Brooks and Culebras reached a similar optimistic conclusion in their comparison of total pancreatectomy with Whipple's operation.

On balance, then, it seems that if at laparotomy the growth is advanced with obvious metastases, or frozen section biopsy of lymph nodes around the pancreas shows metastatic spread, then a palliative bypass should be constructed. If, however, the glands are clear and the tumour is localised or has affected only local structures by direct extension, then the more radical procedure of total pancreatectomy should be considered, especially in younger patients. Even given its increased postoperative morbidity, on present evidence this procedure gives a better chance of cure than the more orthodox Whipple's operation.

Morgan, R G H, and Wormsley, K G, Gut, 1977, 18, 580.

2 Krain, L S, fournal of Surgical Oncology, 1970, 2, 115.

3 Sandlow, L J, and Necheles, H, Gut, 1966, 7, 640.

4 Osnes, M, Serck-Hanssen, A, and Myren, J, Scandinavian fournal of Gastroenterology, 1975, 10, 829 .

Cotton, P B, Gut, 1977, 18, 316

${ }^{6}$ MacGregor, A M, and Hawkins, I F, Surgery, Gynecology and Obstetrics, 1973, 137, 917.

' Banwo, O, Versey, J, and Hobbs, J R, Lancet, 1974, 1, 643.

${ }^{8}$ Pliam, M B, and ReMine, W H, Archives of Surgery, 1975, 110, 506.

${ }^{9}$ Brooks, J R, and Culebras, J M, American fournal of Surgery, 1976, 131, 516.

\section{Challenging clinical judgment}

"Consumerism" has yet to reach the extremes in Britain that can be seen in the United States, where complaints by customers, clients, participants, and patients have grown to the status of a major industry. Even so, there has been a steady flow of legislation and regulations from Westminster giving protection and providing complaints procedures for employees and minority groups, and there are several pressure groups calling for easier access to these procedures for NHS patients and their relatives.

Against that background the report of a parliamentary select committee on hospital complaints ${ }^{1}$ should be seen as an honest attempt to reconcile the conflicting interests of NHS staff and the public-and there is no doubt that conflicts do exist.
As yet complaints about hospital treatment in Britain are relatively uncommon: the 17000 made in 1976 amount to one for every 300 patients admitted to hospital. Nevertheless, the numbers are growing and some of the cases that were described in the first report of the Health Service Commissioner ${ }^{2}$ were so commonplace that there may well be an exponential growth once the procedures available become more widely known. Whenever a patient dies the grief experienced by his or her family is likely to include elements of guilt which may provoke hostility and complaints. Looking for someone to blame is a common, natural, and understandable reaction.

Not so long ago the response of the medical profession to complaints of this kind was a period of conciliation followed by an ultimatum to "sue or shut up." The law provides a mechanism for a patient or his relatives to claim damages where a doctor has been negligent, and clinicians have been adamant that they should not be exposed to any system of quasijudicial investigation in parallel. That viewpoint was acknowledged by the specific exclusion of matters of clinical judgment from the terms of reference of the NHS Commissioner. However, despite listening to medical evidence in support of that approach from the Joint Consultants Committee, the Parliamentary Select Committee has recommended that in future the exclusion should no longer apply. The MPs seem to have been swayed by the chairmen of the regional health authorities, who argued that there was an important distinction between providing damages for injuries and the investigation of a complaint, which they saw as being "aimed at remedying a situation."

What are the facts, however? Common complaints heard last year by the Health Service Commissioner concerned the discharge of old people from hospital to relatives reluctant to accept them and the length of time spent on waiting lists. Whether or not a patient needs to be in hospital and the urgency of an operation are both matters of clinical judgment: are doctors now to have to justify such decisions every time a patient or relative is aggrieved? Anyone who believes that the complaints procedure does not concern itself with trifles should read the three pages in the last report dealing with a complaint that an enema had been given to a patient against his wishes or the two pages on a complaint that a hospital had refused to provide ambulance transport home and had refused to refund the patient his taxi fare.

Certainly hospitals should have a simple, straightforward system for handling complaints; relatives should be heard sympathetically and treated with courtesy and patience. Beyond that point, however, dangerous precedents may be set. Just as there is no limit (other than waiting lists) to the demand for medical care that is free at the time of its provision, so may there be no limit to the numbers of complaints from patients and their relatives-especially in a climate of opinion that encourages challenges to authority. The defence of "clinical judgment" has provided doctors with a legitimate shelter; some of those who have hidden behind it may have been at fault, but most have been simply busy and more concerned with their day-to-day work than with dealing with litigious complainers. Furthermore-and most importantNHS doctors are beginning to look at ways of improving clinical standards through voluntary medical audit. An openended complaints procedure that includes clinical judgment could provoke a wave of reaction that might postpone audit for another generation.

\footnotetext{
${ }^{1}$ First Report from the Select Committee on the Parliamentary Commissione for Administration. London, HMSO, 1977.
}

First Report of the Health Service Commissioner. London, HMSO, 1976. 